\title{
AMENDMENTS
}

\section{Author Correction: Remote sensing northern lake methane ebullition}

\author{
M. Engram (D), K. M. Walter Anthony (D), T. Sachs (D), K. Kohnert (D), A. Serafimovich (D), G. Grosse D and F. J. Meyer (D) \\ Correction to: Nature Climate Change https://doi.org/10.1038/s41558-020-0762-8, published online 11 May 2020.
}

The following code availability statement had not previously been provided for this Letter: "The eddy4R v0.2.0 eddy-covariance software framework used to generate airborne flux estimates is described in ref. ${ }^{56}$ and can be freely accessed at https://github.com/NEONScience/ eddy4R. The eddy4R Environmental Response Functions v0.0.5 advanced software module of ref. ${ }^{49}$ was accessed under Terms of Use for this study (https://www.eol.ucar.edu/content/cheesehead-code-policy-appendix) and is available upon request." As a result, a new ref. ${ }^{56}$ has been added "Metzger, S. et al. eddy4R 0.2.0: a DevOps model for community-extensible processing and analysis of eddy-covariance data based on R, Git, Docker, and HDF5. Geosci. Model Dev. 10, 3189-3206 (2017)". In addition, the following sentence was not included in the Acknowledgements: "We thank S. Metzger for processing the airborne EC raw data and for advice on the machine-learning steps in creating the regional airborne EC flux map using the free eddy $4 \mathrm{R}$ software framework." The online versions of this Letter have now been amended.

Published online: 31 July 2020

https://doi.org/10.1038/s41558-020-0882-1

(c) The Author(s), under exclusive licence to Springer Nature Limited 2020

\section{Author Correction: Increased impacts on US West Coast}

Hien X. Bui (iD

Correction to: Nature Climate Change https://doi.org/10.1038/s41558-020-0828-7, published online 29 June 2020.

In the version of this News \& Views article originally published, in the sentence beginning "Phase 1 exhibits convection..., the first mention of 'Pacific Ocean' should have been 'Indian Ocean'. The sentence should have read "Phase 1 exhibits convection and rainfall over the Indian Ocean, and the phase number increases as it travels east, eventually reaching the central Pacific Ocean in phase 8." The online versions of the News \& Views article have been corrected.

Published online: 31 July 2020

https://doi.org/10.1038/s41558-020-0884-z

() Springer Nature Limited 2020 